\title{
Transcriptome sequencing revealed candidate genes relevant to mesenchymal stem cells' role in aortic dissection patients
}

\author{
JUNLIN YANG ${ }^{*}$, SILI ZOU*, MINGFANG LIAO and LEFENG QU \\ Department of Vascular Surgery, Changzheng Hospital, Shanghai 200003, P.R. China
}

Received May 28, 2017; Accepted October 13, 2017

DOI: $10.3892 / \mathrm{mmr} .2017 .7851$

\begin{abstract}
Aortic dissection (AD) results from the imbalance between synthesis and degradation of extracellular matrices in aortic wall, which is characterized by chronic inflammation. Mesenchymal stem cells (MSCs) are known for anti-inflammatory and repairing effects and have therefore been studied for treatment for numerous diseases, including AD. However, it is unclear which genes or signaling pathways contribute to MSCs' role in AD. In the present study, RNA sequencing (RNA-seq) was conducted between MSCs from patients with AS (AD-MSCs) and those from age-matched healthy donors (HD-MSCs). RNA-seq revealed 201 differentially expressed genes (DEGs) under the filter of fold change $>2$ and P-value $<0.05$, in which 93 genes were upregulated and 108 downregulated. We selectively verified 9 out of 201 DEGs via reverse transcription-quantitative polymerase chain reaction (RT-qPCR) with an enlarged sample size. The trends of RT-qPCR results were consistent with RNA-seq data. Unsupervised hierarchical clustering of the 9-gene expression profiles enables the division of clinical samples into AD and HD groups. Kyoto Encyclopedia of Genes and Genomes analysis displayed a significant change in adhesion-related signaling pathways in AD-MSCs compared with HD-MSCs, whereas gene ontology analysis demonstrated DEGs were enriched in functions associated with development and morphogenesis, from a functional perspective. The present results indicate that gene expression profiles of AD-MSCs were significantly changed compared with HD-MSCs. These changes are probably associated with MSCs' adhesion capacity and development. These results may provide important insights into the role of MSCs in AD pathogenesis.
\end{abstract}

Correspondence to: Professor Lefeng $\mathrm{Qu}$, Department of Vascular Surgery, Changzheng Hospital, 415 Fengyang Road, Shanghai 200003, P.R. China

E-mail: qulefeng.czhospital@gmail.com

*Contributed equally

Key words: mesenchymal stem cells, aortic dissection, cell therapy, transcriptome profiling, mRNA differential display

\section{Introduction}

Aortic dissection (AD) is symbolized by a tear in the tunica intima of the aorta and consequently causing blood to flow between layers of aortic wall and forcing the layers apart. It remains a life-threatening disease with high mortality, despite of significant improvements in the diagnosis and surgical repair (1). Degenerative remodeling within the medial layer (2) is considered as the most important pathogenesis factor. It is characterized by the loss of smooth muscle cells (SMCs) (3), destruction of the extracellular matrix (ECM) and a combination of excessive destruction and insufficient repair. Surgical repair or endovascular strategy exists to treat $\mathrm{AD}$ at present. However, the result is not always satisfactory. Although effective in preventing rupture, surgical procedure is invasive and associated with a high mortality and morbidity (4). Endovascular aneurysm repair (EVAR) are minimally invasive interventions, yet they have anatomical and clinical limitations and drawbacks such as endoleaks and graft migrations (5). Therefore, an alternative that reduces surgical invasion and the risk of rupture is needed.

It has been demonstrated that stem cell therapy could not only enhance the stability of the aneurysm sac, but also reduce the inflammatory process and reinforce arterial layers. Mesenchymal stem cells (MSCs) are multipotent stem cells and can home at sites of injury and contribute to tissue repair, and can be easily harvested from bone marrow, adipose tissue. In vitro, MSCs have been shown to differentiate into SMC-like cells upon PDGF-BB stimulation (6), while in vivo to contribute to healing of injured arteries (7). Previous study showed that MSCs could attenuate aortic aneurysm growth in model mice (8). It later had been demonstrated on animals that MSCs stabilize already-formed aortic aneurysms and MSC is a potential therapeutic intervention (9). MSCs attenuate aortic aneurysms on mice and thus offers a promising insight into biologic therapies for future medical treatment of aortic disease in human (10). Our previous animal study (11) demonstrated that bone marrow cells are activated and recruited to diseased aortic wall when AD occurred. Our findings highlight the protective role of bone marrow cells in response to aortic stress and aortic inflammation. Another study for aortic tissues (12) confirmed that stem cells are more abundant in dissected aortic tissue, and differentiation into SMCs within the diseased aortic wall indicate stem cells a potential contributor to aortic repair. 
Given the current studies on MSCs' active role in aortic aneurysm and dissection (13-15), we hypothesis that MSCs in $\mathrm{AD}$ patient might have some deficits thus patients consequently manifest with insufficient repair and thus the repair-destruction balance is broken. As a matter of fact, some researchers suggested that the dysregulation of MSCs' activity may contribute to the disease (16). Thus, we profiled MSCs' gene expression both from AD patients and healthy donors (HD) by transcriptome sequencing/RNA sequencing (RNA-seq) in this study, aiming to discover genes that may play a crucial role in MSCs' possible protective effect on AD. As a technology of next generation sequencing (NGS), RNA-seq is widely used to detect differentially expressed genes (DEGs) between two gene expression patterns. The DEGs from AD-MSCs and HD-MSCs were then selected, validated, and subjected to bioinformatic analyses, including gene ontology analysis, pathway analysis, and network analysis. Analyzing the potential molecular markers and the possible relationship among the DEGs in MSCs will help give further insight into MSCs' role and mechanism in AD.

\section{Materials and methods}

Patient and donor samples. The MSCs of AD patient (AD group, $\mathrm{n}=9$; mean age, $55.0 \pm 9.6$ years) were collected from their sternum bone marrow during surgery while the MSCs of HDs (HD group, $n=6$; mean age, $49.5 \pm 12.2$ years) are harvested from their ilia. Three samples of each group were used for RNA-seq and all the samples were used for quantitative PCR (qRT-PCR) verification. No significant difference in age was found between the AD and HD groups ( $t=0.9775$, $\mathrm{df}=13, \mathrm{P}=0.3461)$. Neither the AD group nor normal control had any history of Marfan syndrome, bicuspid aortic valve or any other aortic pathology. All patients had acute dissections with onset no earlier than 14 days before surgery. All of them were confirmed to have Stanford type B AD by preoperative examination or surgery. All the patients with hypertension $(n=9)$ were taking antihypertensives for at least 3 months before operation. Among them, 5 were taking calcium channel blockers, 4 were taking diuretics, and 2 were taking angiotensin-converting enzyme inhibitors. Neither statins nor other relevant medications were taken. A detailed sample description is recorded in Table I.

The study was approved by the Ethics Committee of Changzheng Hospital, and all patients gave informed consent. All samples used in this study were prepared in parallel based on published methods.

Isolation of MSCs. The general procedures are referred to published literatures. Density gradient centrifugation was applied to bone marrow from both the AD patients and HD by using Ficoll (Ficoll-Paque Premium 1.073; GE Healthcare Bio-Sciences AB, Piscataway, NJ, USA). Detailed procedures are followed by manufacturer's protocol.

The mononuclear cells obtained after centrifugation were plated in non-coated 10-cm culture dish in low-glucose Dulbecco's modified Eagle's medium (DMEM-LG; Invitrogen, Carlsbad, CA, USA) supplemented with $5 \%$ UltraGRO $^{\mathrm{TM}}$-Advanced Cell Culture Supplement (AventaCell BioMedical Co., Ltd., Atlanta, GA, USA) with no penicillin or streptomycin. The
Table I. Patient information.

\begin{tabular}{lccccc}
\hline $\begin{array}{l}\text { Laboratory } \\
\text { code }\end{array}$ & Sex & Age & Group & RNA-seq & qRT-PCR \\
\hline 1 & M & 62 & HD & Yes & Yes \\
2 & F & 46 & HD & Yes & Yes \\
3 & F & 34 & HD & Yes & Yes \\
4 & F & 55 & AD & Yes & Yes \\
5 & F & 59 & AD & Yes & Yes \\
6 & M & 71 & AD & Yes & Yes \\
7 & F & 37 & HD & No & Yes \\
8 & M & 60 & HD & No & Yes \\
9 & F & 58 & HD & No & Yes \\
10 & M & 48 & AD & No & Yes \\
11 & F & 59 & AD & No & Yes \\
12 & F & 59 & AD & No & Yes \\
13 & M & 57 & AD & No & Yes \\
14 & M & 36 & AD & No & Yes \\
15 & F & 51 & AD & No & Yes \\
\hline
\end{tabular}

M, male; F, female; HD, healthy donor; AD, aortic dissection; qRT-PCR, quantitative PCR.

cells were cultured at $37^{\circ} \mathrm{C}$ in a humidified atmosphere of $5 \%$ $\mathrm{CO}_{2}$. Non-adherent cells were removed from the culture dish after 2 days, and the medium was changed every other day until the cultured MSCs reached 90\% confluence (passage 0). Then, MSCs were removed from the dish by treatment with $0.05 \%$ trypsin (Invitrogen) for $30 \mathrm{sec}$ at $37^{\circ} \mathrm{C}$ and then replated in another culture dish at a density of $2,000 \mathrm{cells} / \mathrm{cm}^{2}$ (passage 1). When $90 \%$ confluence was obtained, the cells were trypsinized and replated in another fresh culture dish (passage 2). These processes were repeated up to passage 2, when MSCs were used for all experiments.

Identification of MSCs. To confirm the multipotentiality of MSCs used in our research, experiments were performed in accordance with the minimal criteria for defining multipotent MSCs proposed by the International Society for Cellular Therapy (ISCT) (17).

The cultured plastic-adherent cells expressing the markers CD73 (sic passim; eBioScience, San Diego, CA, USA), CD90 and CD105 but not expressing the markers CD14, CD19, CD34, CD45 and HLA-DR were able to differentiate into adipocytes, osteoblasts and chondrocyte induced by products of Stem Cell Technologies (Vancouver, BC, Canada), which are respectively MesenCult $^{\mathrm{TM}}$ Adipogenic Differentiation Medium (human) and MesenCult ${ }^{\mathrm{TM}}$ Osteogenic Stimulatory kit (human) and MesenCult ${ }^{\mathrm{TM}}$-ACF Chondrogenic Differentiation Medium. Manufacturer's manuals were referred.

To determine whether the expanded MSC cultures maintained multipotency differentiation characteristics, we tested both HD-MSCs and AD-MSC for differentiation into adipogenic, osteogenic and chondrogenic cell lines. MSCs cultured in adipogenic differentiation medium showing lipid droplets were stained by Oil Red O staining. Osteogenic differentiation 
Table II. qRT-PCR primers for the 9 selected DEGs.

\begin{tabular}{lll}
\hline Gene & \multicolumn{1}{c}{ Forward primer $\left(5^{\prime}-3^{\prime}\right)$} & Reverse primer $\left(5^{\prime}-3^{\prime}\right)$ \\
\hline GAPDH & GTCAACGGATTTGGTCGTATTG & TGGAAGATGGTGATGGGATTT \\
ABCA4 & GGTTCCTGGACAGCTTCTCC & CCAGACTGGCCTTGGAGAAG \\
CXCL1 & TCCTGCTCCTGGTAGCCG & TCCGCCCATTCTTGAGTGTG \\
CXCL5 & GTCCTTCGAGCTCCTTGTGC & CGTTCTTCAGGGAGGCTACC \\
EMX2 & ACCTTCTACCCCTGGCTCAT & GGCGTGTTCCAGCCTTAGAA \\
HTR7 & TGGTGATCTCCGTGTGCTTC & CTGATCACGCACAGGGTCAT \\
IGFBP2 & TTCCGGGAGAAGGTCACTGA & GAGGTTGTACAGGCCATGCT \\
NCAM1 & CTGGAGGACTTCTACCCGGA & TGGTTCCCCTCCCAAGTGTA \\
SNAP25 & GCCTTCACCAAGAGCGAAAC & CTCAGGCAGCAGAACGTACA \\
\hline
\end{tabular}

qRT-PCR, quantitative PCR; DEG, differentially expressed gene.

was demonstrated by calcium deposition, which was stained by Alizarin Red S. Histological sections of chondrogenic pellet were stained with Alcian Blue and Nuclear Fast Red. Undifferentiated AD-MSCs and HD-MSCs were used as controls.

Proliferation assay. Cell proliferation was assessed with the Cell Counting kit-8 (CCK-8) assay (Beyotime Institute of Biotechnology, Haimen, China). Cells were seeded onto 96-well plates $\left(1 \times 10^{3}\right.$ cells/well) and then OD at $450 \mathrm{~nm}$ was measured from the 1 st day to the 7 th day after addition of $10 \mu \mathrm{l}$ of CCK-8 solution to each well and a sequential incubation for $1 \mathrm{~h}$ at $37^{\circ} \mathrm{C}$. The assay was performed in triplicate.

Cell cycle assay. The cell cycle was analyzed using propidium iodide (PI; Sigma-Aldrich, St. Louis, MO, USA) as described by Nicoletti et al (18). The cell cycle was blocked by reducing FBS to $0.1 \%$ for $24 \mathrm{~h}$, and then the concentration of FBS was returned to $10 \%$. Three days later, the cells were harvested for cell cycle analysis. First, the cells were washed and fixed overnight in cold ethanol (70\%). Then, the fixed cells were washed and reconstituted in $250 \mu \mathrm{l}$ of buffer $(0.1 \% \mathrm{NP} 40,0.2 \mathrm{mg} / \mathrm{ml}$ RNase, and $0.2 \mathrm{mg} / \mathrm{ml} \mathrm{PI}$ ) and incubated for $30 \mathrm{~min}$ at $4^{\circ} \mathrm{C}$. Ten thousand events were collected from each sample using a FACSCalibur flow cytometer (BD Biosciences, San Jose, CA, USA). All experiments were performed in triplicate. The data were analyzed using CellQuest software (BD Biosciences).

RNA-seq. Total RNA from MSC cultures in passage 2 was obtained using EZNA ${ }^{\circledR}$ Total RNA kit I (Omega Bio-Tek, Inc., Norcross, GA, USA) according to the manufacturer's instructions.

The RNA-seq was commercially commissioned to Jia Laboratory (Life Science Institute, Zhejiang University, Hangzhou, China). The data were generated by Hiseq 2500 through NGS in fast mode as single end. After sequencing completing, configureBclToFastq.pl, a perl script from illumina ${ }^{\circledR}$, was run to get reads data in fastq format. Then we used Tophat to map reads against hg19 reference transcript and genome. Through our laboratory pipeline we counted each sample's reads mapped to each gene of hg19, and got the result of difference expression of genes through edgeR package (dispersion $=0.04$, other parameters used as default).

Quantitative PCR (qRT-PCR). qRT-PCR analyses were performed using $500 \mathrm{ng}$ of mRNA treated with EZNA ${ }^{\circledR}$ Total RNA kit I and reverse transcribed with ReverTra Ace ${ }^{\circledR}$ qPCR RT Master mix with gDNA Remover (Toyobo Co., Ltd., Osaka, Japan). Each reaction was performed with $10 \mu \mathrm{l}$ of EvaGreen qPCR Mastermix (Applied Biological Materials Inc., Richmond, BC, Canada), $5 \mu 1$ of cDNA (100 ng of cDNA), $0.5 \mu \mathrm{l}$ each primer $(10 \mu \mathrm{M})$ and $4 \mu \mathrm{l}$ of $\mathrm{ddH}_{2} \mathrm{O}$. The quantitative determination of mRNA levels was performed using The Infinite ${ }^{\circledR} 200$ PRO NanoQuant (Tecan Trading AG, Männedorf, Switzerland). The reactions were performed in CFX Connect ${ }^{\mathrm{TM}}$ Real-Time PCR Detection system (Bio-Rad Laboratories, Inc., Philadelphia, PA, USA) using the following program: $95^{\circ} \mathrm{C}$ for $10 \mathrm{~min}$, followed by 40 cycles at $95^{\circ} \mathrm{C}$ for $10 \mathrm{sec}, 60^{\circ} \mathrm{C}$ for $20 \mathrm{sec}$ and $72^{\circ} \mathrm{C}$ for $15 \mathrm{sec}$, and then a final extension at $65^{\circ} \mathrm{C}$ to $95^{\circ} \mathrm{C}$ with increment of $0.5^{\circ} \mathrm{C}$ for 5 sec. Dissociation curve analysis was used to demonstrate equal amplification efficiency of a specific PCR product for all primers used in this study; all primers demonstrated equal amplification efficiency and specific PCR products through dissociation curve analysis. The determination of fold expression change was calculated using Livak's $\Delta \Delta \mathrm{C}_{\mathrm{T}}$ method. Expression levels were estimated in triplicate, and GAPDH were used as normalization genes. The primers of tested genes are listed in Table II.

Statistical analysis. Parametric data were expressed as mean \pm standard deviation (normally distributed) or median with inter-quartile range (not normally distributed) and evaluated by Student's t-test or ANOVA with Tukey's honest significant difference method for comparisons between groups if possible. Wilcoxon test (also known as Mann-Whitney test) or Kruskal-Wallis Rank Sum test was likewise performed for non-parametric data. Shapiro-Wilk test and Bartlett test are performed for normality and homogeneity of variance respectively. All statistical analyses are conducted using $\mathrm{R}$ [R Core Team (2017). R: A language and environment for 

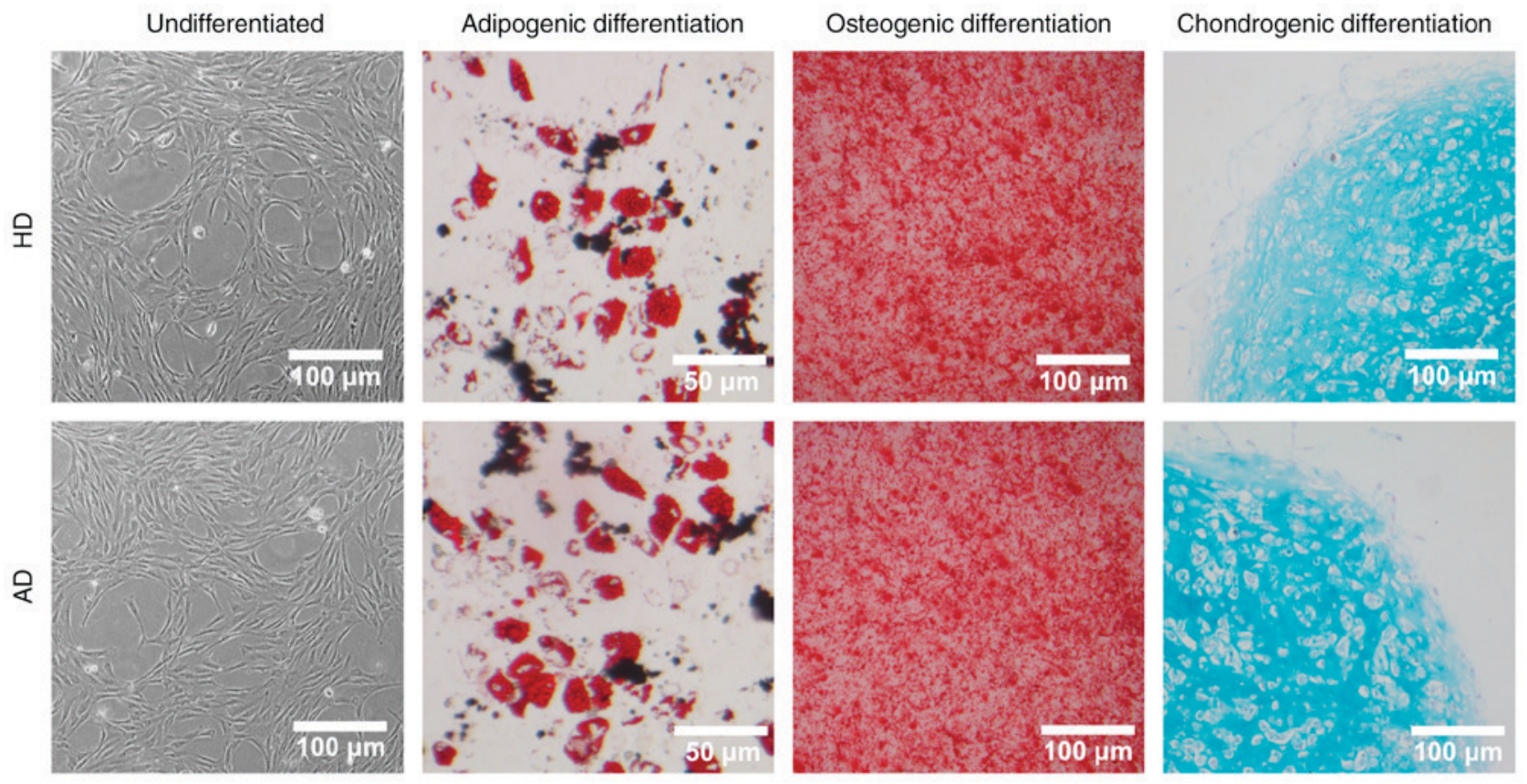

Figure 1. MSC morphology and differentiation capacity identification. MSC, mesenchymal stem cells; HD, healthy donor; AD, aortic dissection.

statistical computing. R Foundation for Statistical Computing, Vienna, Austria; https://www.R-project.org/] or GraphPad Prism $^{\mathrm{TM}}$ software (GraphPad Software, Inc., La Jolla, CA, USA). Probability values of $<5 \%$ were considered significant. All experiments were conducted in triplicate. Basic analysis of RNA-seq data is done by Jia Laboratory and advanced analysis (including KEGG/GO enrichment and PPI analysis) is done by Guangzhou RiboBio Co., Ltd. (Guangzhou, China).

\section{Results}

In vitro characterization of MSC cultures. After isolation and adherence to cell culture dishes, MSCs were morphologically spindle-shaped, as is shown in Fig. 1. The identity of the MSCs was determined by confirming the panel of surface markers (positive for CD90, CD73 and 105; negative for CD45, CD34, CD14, CD19 and HLA-DR in Fig. 2) and multipotency capacity of differentiation into adipogenic, osteogenic and chondrogenic cells (Fig. 1).

AD-MSCs displayed conserved proliferation and cell cycle profiles compared with HD-MSCs. To verify whether AD-MSCs presented changes in their proliferation potential and had cell cycle arrest, we performed cell proliferation and flow cytometry assays and compared the results with those of HD-MSCs. As observed in Fig. 3, no significant alterations were observed for proliferation and cell cycle profiles of all MSC cultures. These results indicate that MSC cultures conserved their proliferation capacity despite the disease condition.

AD-MSCs molecular profile. Although AD-MSCs conserved their proliferation profile, the molecular pattern of these cells could differ from that of HD-MSCs. Thus, we determined the global gene expression pattern for AD-MSCs and compared it with that for HD-MSCs. We performed
Table III. The number of DEGs varies in correspondence with the alteration of filters.

\begin{tabular}{lccc}
\hline Filters & $\begin{array}{c}\text { No. of } \\
\text { DEGs }\end{array}$ & $\begin{array}{c}\text { Up- } \\
\text { regulated }\end{array}$ & $\begin{array}{c}\text { Down- } \\
\text { regulated }\end{array}$ \\
\hline $\mathrm{P}<0.05, \mathrm{FC}>2$ & 201 & 93 & 108 \\
$\mathrm{P}<0.05, \mathrm{FC}>4$ & 56 & 30 & 26 \\
$\mathrm{P}<0.01, \mathrm{FC}>2$ & 60 & 28 & 32 \\
$\mathrm{P}<0.01, \mathrm{FC}>4$ & 30 & 12 & 18 \\
\hline
\end{tabular}

DEG, differentially expressed gene; FC, fold change.

a comparative transcriptome analysis using an expression profiling sequencing.

In this assay, 3 samples from different AD-MSCs were compared with 3 from HD-MSCs. After the second passage, total RNA was obtained from each MSC culture, and then RNA-seq was conducted. Using a $\geq 2$-fold change (FC) and $<0.05 \mathrm{P}$-value as a cut-off to define overexpression or downregulation, 201 genes were found to be differentially expressed in all RNA-seq. Notably, 93 of these 201 genes were overexpressed in AD-MSCs, while 108 of these genes were downregulated. The number of DEGs varies along with the alteration of filters: a stricter filter results in a smaller DEGs profile. Table III shows some common filters and corresponding DEGs size. As is shown in Fig. 4, the volcano plot (Fig. 4A) intuitively exhibited the distribution of DEGs and the hierarchical clustering in the heatmap (Fig. 4B) of these DEGs suggests that a common molecular signature exists for all AD-MSCs compared to HD-MSCs. The filter for volcano plot and heatmap in Fig. 4 was $\mathrm{P}<0.01$ and $\mathrm{FC}>4$ on account of the readability. A stricter filter results in a small number of DEGs, which makes the plot easier to recognize. 

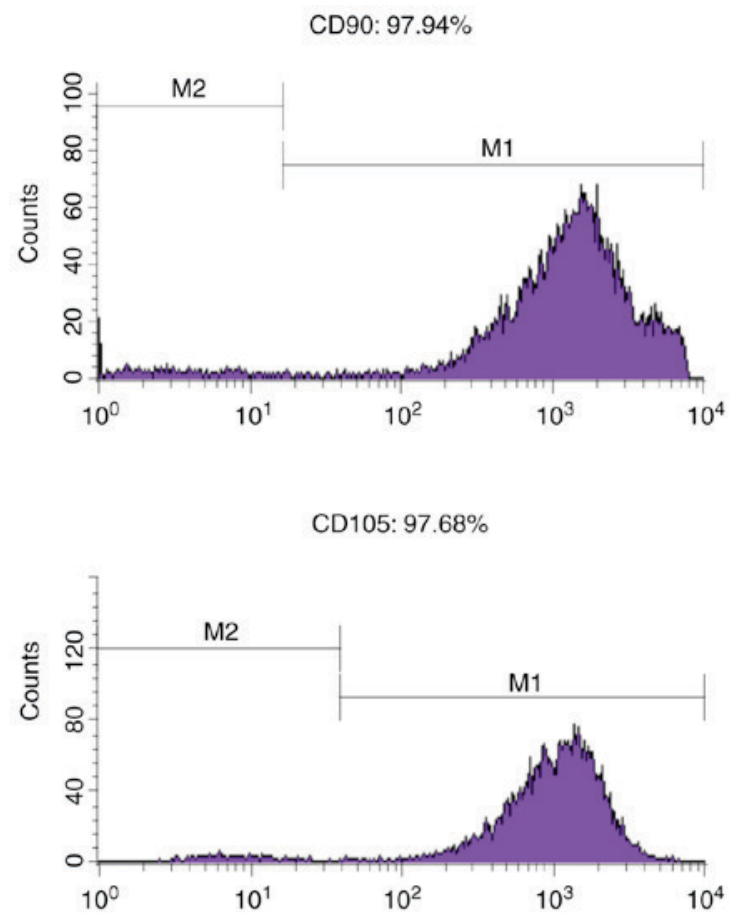

CD34: $0.16 \%$

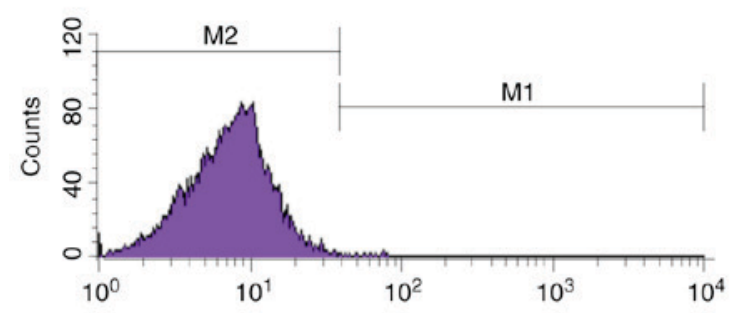

CD19: $0.00 \%$

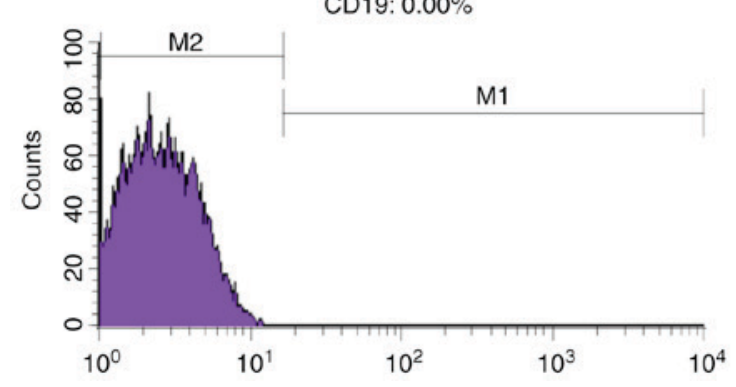

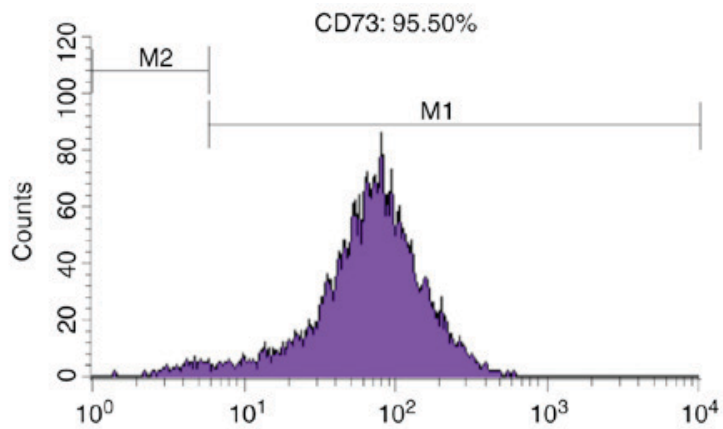

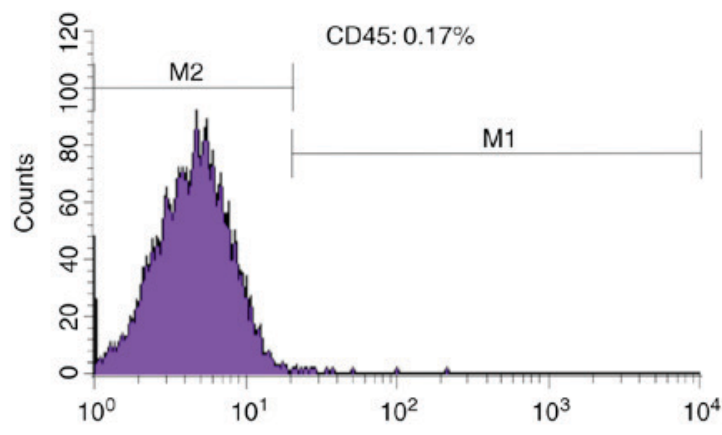

CD14: $0.48 \%$

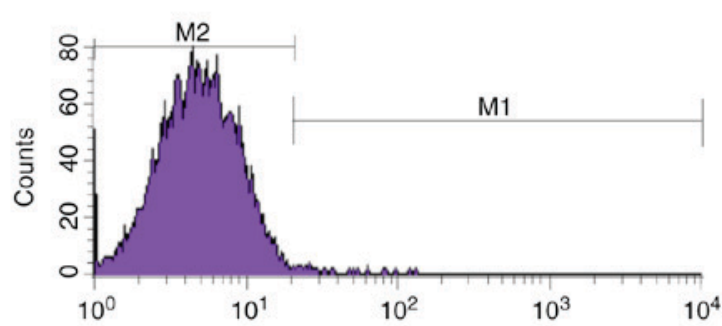

HLA-DR: $1.59 \%$

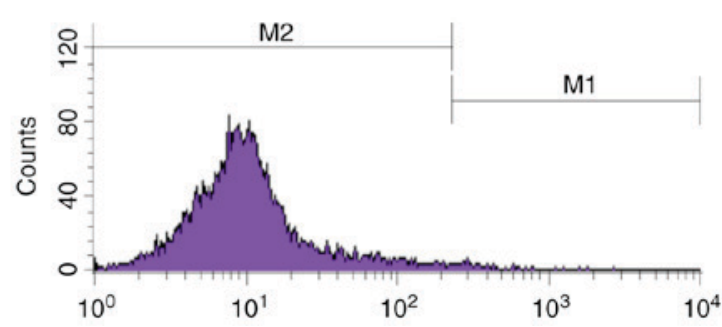

Figure 2. Surface antigen identification by flow cytometry.

Further analysis of these results showed that the genes found altered in AD-MSCs function in important signaling pathways involved in MSCs' function. As is shown in KEGG analysis (Fig. 5), DEGs are involved primarily in cell adhesion molecules (CAMs), ECM-receptor interaction, focal adhesion and TGF- $\beta$ signaling etc. GO analysis (Fig. 6) revealed DEGs are enriched mainly in multicellular organismal development, system development, organ development, anatomical structure morphogenesis etc. Both KEGG and GO analysis illustrated AD-MSCs may have some deficits in development or adhesion function.

qRT-PCR confirmed the molecular signature of AD-MSCs. To confirm the obtained RNA-seq results, qRT-PCR of some overexpressed and downregulated genes was performed. In this case, the analysis was performed with a larger sample size: 6 AD-MSCs samples and 9 HD-MSCs samples. The age is normally distributed (HD-MSCs: $\mathrm{W}=0.87117, \mathrm{P}=0.2309$; AD-MSCs: $\mathrm{W}=0.93065, \mathrm{P}=0.4875)$ and balanced between two groups (HD-MSCs: $n=6$, mean age, 49.5 \pm 12.3 years; AD-MSCs: $\mathrm{n}=9,55.0 \pm 9.6$ years; $\mathrm{t}=0.9282, \mathrm{df}=8.988, \mathrm{P}=0.3776$ ). The overexpressed genes, i.e., CXCL1, CXCL5, HTR7 and $S N A P 25$, and the downregulated genes, i.e., EMX2, NCAM1 and $I G F B P 2$ were used in this analysis. Detailed information about the 9 genes are listed in Table IV. These genes were chosen because all of them had been previously described as related to MSCs functions or AD pathogenesis. For example, 

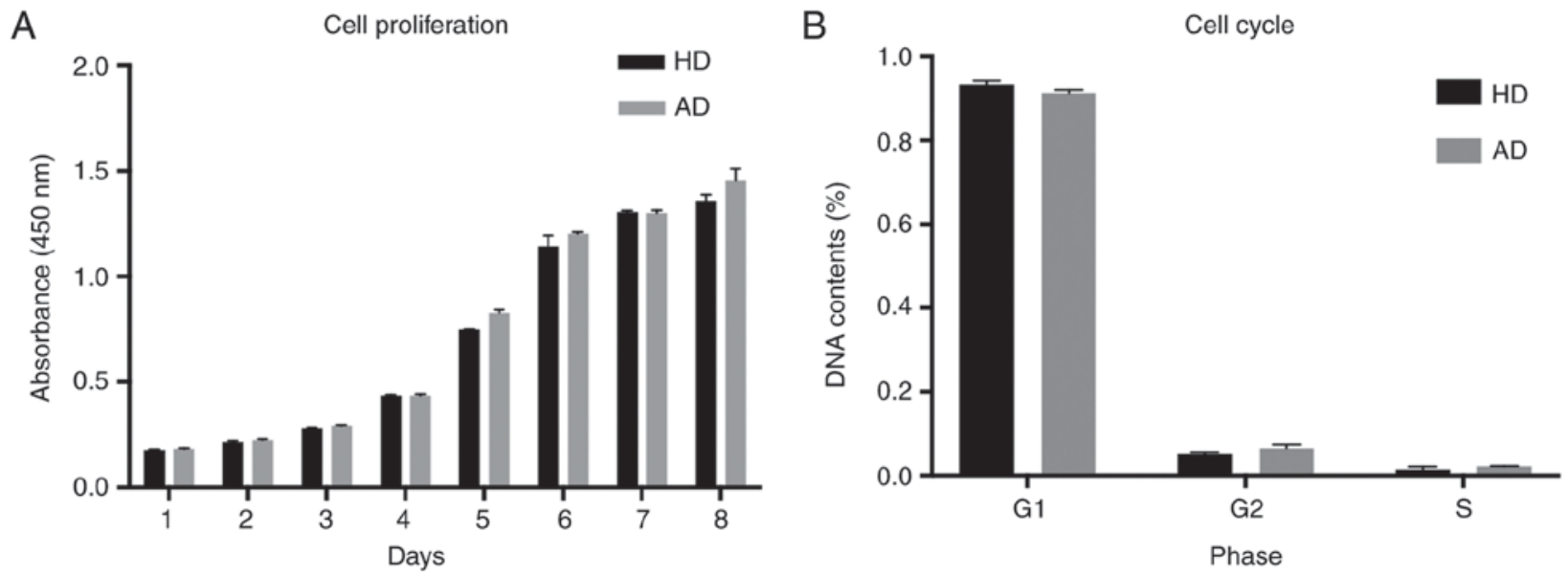

Figure 3. Cell proliferation and cell cycle assay for HD-MSCs and AD-MSCs. (A) Cell proliferation profiles were determined from day 1 to day 8 by CCK-8 assay. As is shown, the proliferation was identical for all MSC cultures; no significant alterations were observed. The result indicates that AD-MSC cultures conserved their proliferation capacity. (B) Using the same samples, flow cytometry was used to analyze the cell cycle. As is shown, cell cycle profiles were identical for all MSC cultures, no significant alterations were observed. The result indicates that AD-MSC cultures conserved their cell cycle pattern compared with HD-MSC cultures. MSC, mesenchymal stem cells; HD, healthy donor; AD, aortic dissection; CCK-8, Cell Counting kit-8.

A

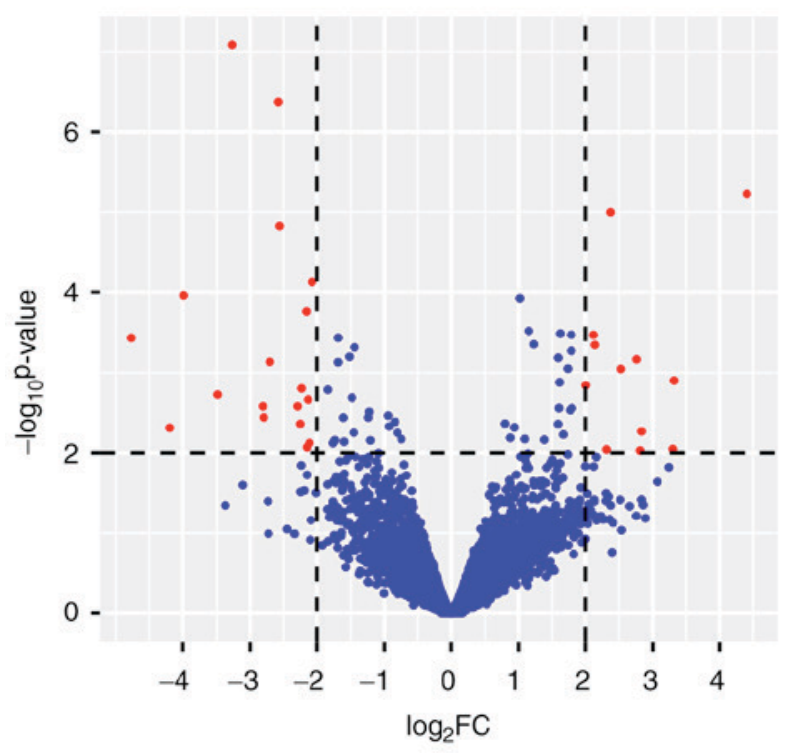

B

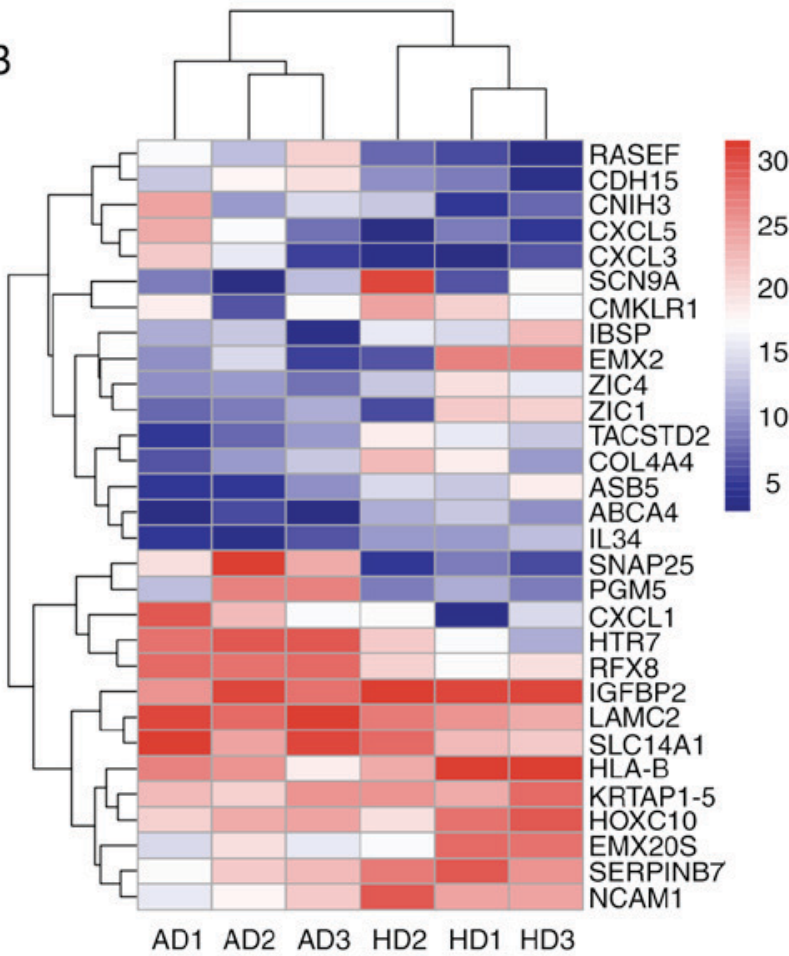

Figure 4. Visualization of DEGs between AD-MSCs and HD-MSCs identified by RNA-seq assay. (A) A volcano plot. Red plots represented significant $(\mathrm{P}<0.01)$ and remarkable $(\mathrm{FC}>4)$ DEGs, while blue plots represented insignificant $(\mathrm{P} \geq 0.01)$ or unremarkable $(\mathrm{FC} \leq 4) \mathrm{DEGs}$. (B) A heatmap and hierarchical clustering analysis. the color represented gene expression level hierarchical clustering analysis classified samples (MSCs) and indices (genes) step by step, according to their similarities. The results showed a molecular signature for AD-MSCs compared to HD-MSCs. DEG, differentially expressed gene; AD, aortic dissection; MSC, mesenchymal stem cells; HD, healthy donor; RNA-seq, RNA sequencing; FC, fold change.

both CXCL/CXCR signal axis and IGFBP/IGF-signaling pathway are highly related to MSCs' function, which will be discussed later. As is illustrated in Fig. 7, qRT-PCR validation for 9 selected DEGs were consistent with the RNA-seq results (Fig. 7A), so was western blotting validation for 2 selected DEGs (Fig. 7C). The hierarchical clustering analysis using the 9-gene panel, acting as unsupervised learning, could even spontaneously divided MSC samples into HD and AD groups correctly (Fig. 7B).
Analysis of PPI network and functional annotation of genetic biomarkers for $A D-M S C$. We queried STRING database of 30 most statistically significantly DEGs of AD by applying a stricter filter $(\mathrm{P}<0.01$ and $\mathrm{FC}>4)$. As a result, functional modules were shown in Fig. 8. Some genes are not shown because no interactions were observed in the database. Our data implied that CAMs (e.g., NCAMI) that were interacted with chemokines ( $C X C L 1)$, might be account for the MSCs' functional changes. Another interaction network is 

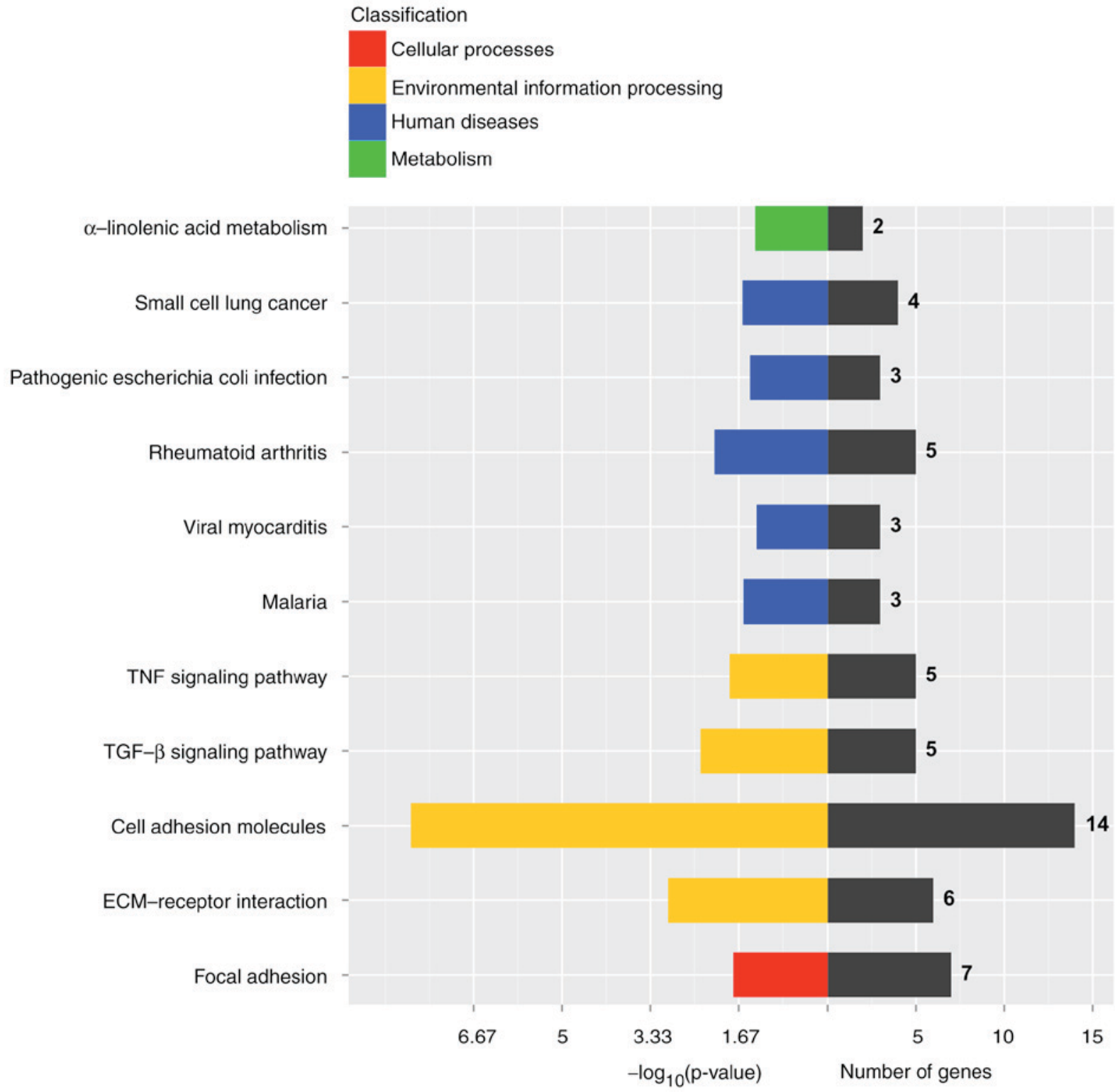

Figure 5. KEGG pathway analysis. The analysis of KEGG pathway between AD-MSCs and HD-MSCs for the most statistically significant DEGs (under the filter of $\mathrm{P}<0.05$ and $\mathrm{FC}>2$ ). The left side of $\mathrm{x}$-axis shows-lg ( $\mathrm{P}$-value) and the right side shows the number of genes. The larger-lg (P-value) indicated a smaller P-value. The y-axis shows KEGG pathways category. AD, aortic dissection; MSC, mesenchymal stem cells; HD, healthy donor; DEG, differentially expressed gene; FC, fold change.

collagen-related molecules. Collagen, as well as elastin, is the main component of aorta. This network implies MSCs may have some effect on collagen in AD pathogenesis.

\section{Discussion}

The exact etiological mechanisms are not fully established. As far as we know, AD is characterized by chronic inflammation especially atherosclerotic changes and develops as a result of ECM destruction within the aortic wall, where the infiltrating macrophage release matrix metalloproteinases (MMPs), inflammatory cytokines and chemokines, leading to a loss of elastin in the aortic wall (19). In human histological studies, increasing aneurysm diameter and rupture was associated with a higher density of inflammatory cells in the adventitia. Various stimuli have been linked to chronic inflammation observed in AD. Therefore, the control of inflammation may be an alternative strategy for treatment of AD. A number of experimental investigations and clinical studies have attempted to treat aortic disease using various drugs and factors to control the inflammation, for example, angiotensin converting enzyme inhibitor and statin $(20,21)$, doxycycline $(22,23)$, nonsteroidal anti-inflammatory drugs (24) and c-jun N-terminal kinase inhibitor (25). However, these pharmacotherapies have still not been established for clinical application because of their side effects caused by systemic administration of these agents. Another disadvantage of using these agents is that special equipment might be required to deliver them locally for the treatment. Cell therapy with MSCs seem to be free of severe systemic adverse reactions and the homing capacity makes MSCs a 'targeted drug'. As is mentioned above, cell therapy could not only enhance the stability of the aneurysm sac, but also reduce the inflammatory process and developing new reinforced arterial layers in animals. Many researches have 
Table IV. Detailed information of the 9 selected DEGs, including expression level (reads), FC and P-values acquired via RNA sequencing assay.

\begin{tabular}{lrrrrrrrrr}
\hline Gene ID & HD1 & HD2 & HD3 & AD1 & AD2 & AD3 & logFC & P-value & FC \\
\hline SNAP25 & 8 & 9 & 8 & 58 & 518 & 117 & 4.41 & 0.00 & 21.19 \\
CXCL5 & 8 & 5 & 6 & 176 & 45 & 20 & 3.32 & 0.00 & 10.00 \\
CXCL1 & 2 & 57 & 39 & 792 & 151 & 54 & 3.30 & 0.01 & 9.87 \\
HTR7 & 49 & 148 & 27 & 440 & 414 & 539 & 2.37 & 0.00 & 5.17 \\
IGFBP2 & 1,489 & 888 & 2,118 & 331 & 490 & 214 & -2.56 & 0.00 & 0.17 \\
NCAM1 & 189 & 575 & 160 & 43 & 54 & 97 & -2.58 & 0.00 & 0.17 \\
SERPINB7 & 812 & 316 & 495 & 54 & 88 & 114 & -3.26 & 0.00 & 0.10 \\
SCN9A & 7 & 638 & 68 & 10 & 1 & 33 & -4.20 & 0.00 & 0.05 \\
EMX2 & 544 & 14 & 509 & 11 & 36 & 11 & -4.77 & 0.00 & 0.04 \\
\hline
\end{tabular}

DEG, differentially expressed gene; FC, fold change; HD, healthy donor; AD, aortic dissection.

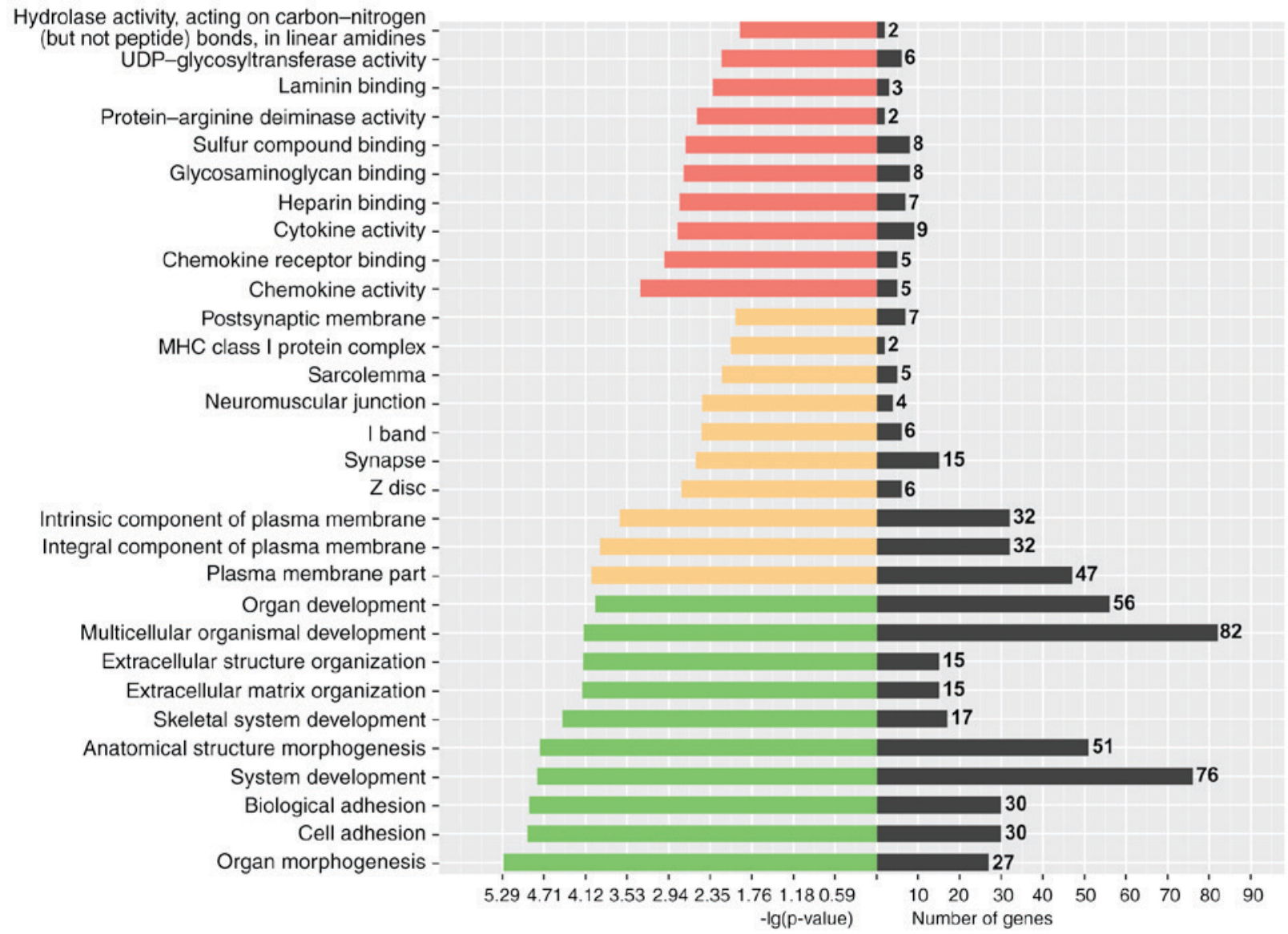

Figure 6. GO term enrichment analyses. The analysis of GO term enrichment between AD-MSCs and HD-MSCs for the most statistically significant DEGs (under the filter of $\mathrm{P}<0.05$ and $\mathrm{FC}>2$ ). The left side of $\mathrm{x}$-axis shows-lg (P-value) and the right side shows the number of genes. The larger-lg (P-value) indicated a smaller P-value. The y-axis shows GO term category. AD, aortic dissection; MSC, mesenchymal stem cells; HD, healthy donor; DEG, differentially expressed gene; FC, fold change.

been focusing on cellular therapies to attempt stabilizing $\mathrm{AD}$ and repairing the lesion, and MSCs are considered as an attractive cell source in cell therapy and tissue engineering (26). As for cell therapy for aortic disease, MSCs were originally thought to differentiate into endothelial and SMCs $(27,28)$ and involved in vascular repair processes, neoangiogenesis and stabilization of injuries (29,30). But MSCs' anti-inflammatory effect seems to account for more. Inflammatory reaction within the aortic wall leads to weakness and degeneration of the vessel. The anti-inflammatory and angiogenic capacity, the ability to release a range of growth factors (especially vascular and fibroblast related), and the regulatory role in MMPs secretion makes MSCs ideal candidates for the treatment of AD. Recent studies have highlighted the critical importance 

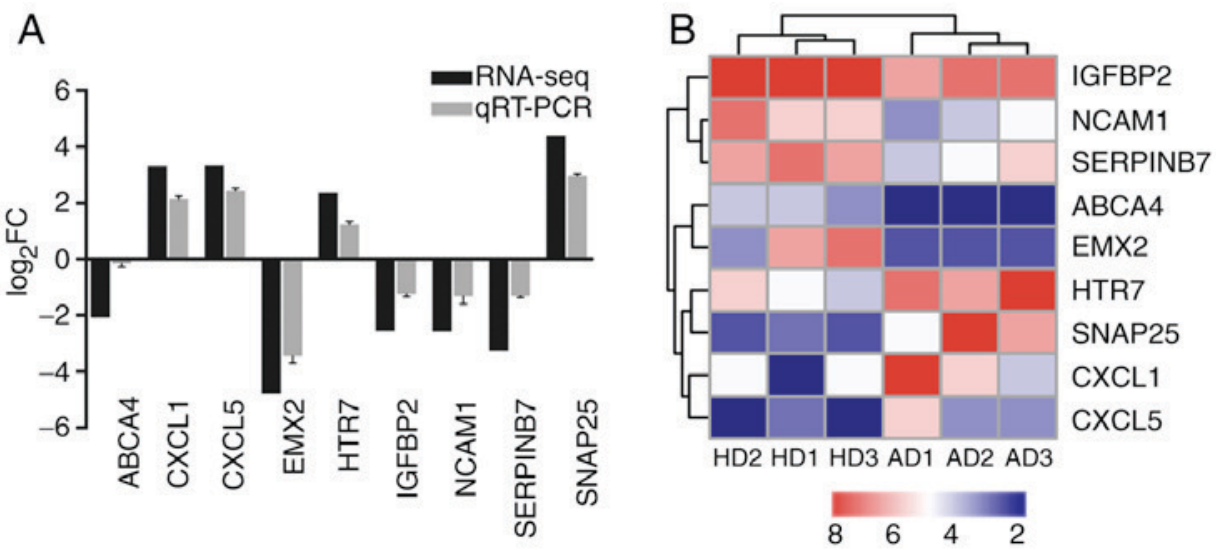

C

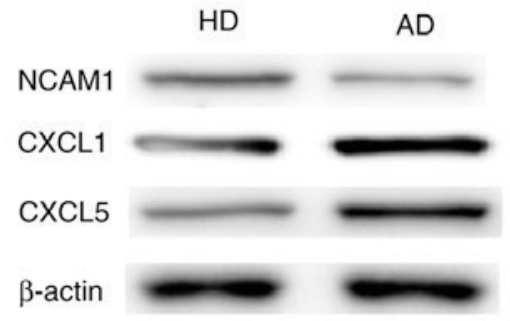

Figure 7. Post RNA-seq validation. To confirm the obtained RNA-seq results, qRT-PCR or western blotting was used to validate some DEGs using a larger sample size to determine changes in mRNA or protein expression levels. (A) qRT-PCR analyses with 9 DEGs and (C) western blot analyses with 2 DEGs went in accordance with the RNA-seq results and; (B) unsupervised hierarchical clustering using qRT-PCR data could spontaneously divide MSCs samples into AD group and HD group. RNA-seq, RNA sequencing; qRT-PCR, quantitative PCR; DEG, differentially expressed gene; MSC, mesenchymal stem cells; AD, aortic dissection; HD, healthy donor; FC, fold change.

of MSCs as essential constituents for the aortic aneurysm or dissection niche through inducing chemokine and cytokine secretion (31) and wound healing $(32,33)$. More and more studies are providing insights into aberrant microenvironment of AD pathology, and MSCs have been recognized as a crucial element for AD microenvironment (14). It has been demonstrated (34) that the capacity of MSCs to protect against aneurysm formation by immunomodulation on $\mathrm{CD} 4^{+} \mathrm{T}$ cell and IL-17.

Since most studies have demonstrated MSCs could protect or repair $\mathrm{AD}$, we could reasonably hypothesize that there might be some deficits with AD-MSCs compared with HD-MSCs. Therefore, we compared bone marrow derived AD-MSCs with HD-MSCs in this study, to further understand MSCs' role in $\mathrm{AD}$ and to provide possible treatment targets. The reason why MSC samples in our study were harvested from bone marrow instead of aortic tissue was mostly technical restriction. As is known, MSCs can be easily harvested from bone marrow, adipose tissue and umbilical cord blood but the derivation from aorta is not reported, probably for its insufficiency in aortic wall. As a matter of fact, our previous study on animal has demonstrated that bone marrow-derived MSCs is recruited to diseased aortic tissue. From our perspective, it is reasonable to test bone marrow-derived MSCs at the second passage as an alternative. The reason why we didn't deploy the protocol of FACS cell sorting direct from bone marrow was mainly for technical barriers, too. As for FACS cell sorting, either positive selection or negative selection is faced with unsolvable problems. Due to the lack of cell specific surface marker of MSCs, we currently have to use a panel of markers to identify MSCs. Negative selection can only eliminate unwanted cells while positive selection would activate the downstream pathway of the surface maker, altering the expression profile. We finally adapted the protocol of primary culturing cells to passage 2 instead of, when all criteria by ISCT (morphology, surface antigen and differentiation capacity) were met. MSCs' basic features including morphology and proliferation showed no significant difference between AD and HD group. But then RNA-seq revealed a molecular profile consisted of 201 DEGs between AD-MSCs and HD-MSCs, suggesting a specific
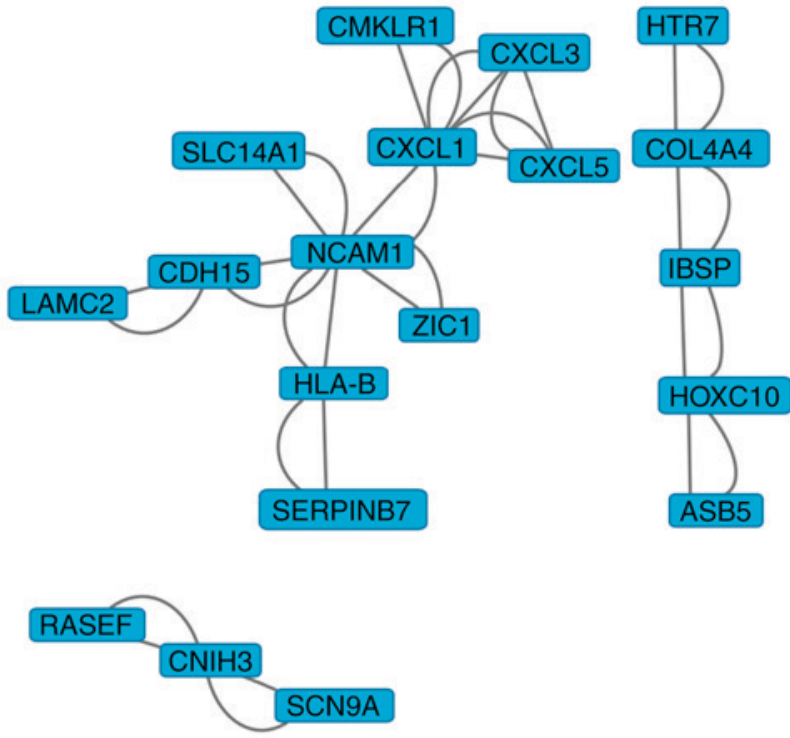

Figure 8. Analysis of PPI of most significant DEGs between AD-MSCs and HD-MSCs. PPI revealed possible interaction mode for most significant DEGs. PPI, protein-protein interaction; DEG, differentially expressed gene; MSC, mesenchymal stem cells; AD, aortic dissection; HD, healthy donor.

AD-MSCs molecular signature. Based on published literature, we finally chose 9 most significant DEGs, naming $A B C A 4$, CXCL1, CXCL5, EMX2, HTR7, IGFBP2, NCAM1, SERPINB7 and SNAP25, for qRT-PCR verification with an enlarged sample size and then made an unsupervised hierarchical clustering analysis to see if this 9-gene molecular profile is also capable of distinguishing AD-MSCs from HD-MSCs. As is shown in Fig. 7B, the 9-gene molecular profile we selected can separate AD-MSCs from HD-MSCs. Either the 209-DEGs or 9-DEGs profile suggests a molecular signature that could even be a possible molecular panel of markers to identify AD-MSCs.

Among the DEGs, a significant target gene revealed by DEGs is CXCL1/5. CXCL/CXCR signal axis is considered as responsible for important functions of MSCs' like migration and immunomodulatory $(35,36)$. It has been reported that $C X C R 4$ has 
been reported to enhance the migration of bone marrow MSCs in vitro in a rat abdominal aortic aneurysms model $(37,38)$, and our findings suggested other genes belonging to CXCL/CXCR family contribute to MSCs' function in AD pathogenesis. IGFBP2 was another differently expressed gene. Previous researchers $(39,40)$ have found that IGFBP/IGF-signaling pathway are responsible for MSCs' migration immunomodulatory and differentiation. Besides, IGFBP2 together with $C X C L 1 / 5$ is responsible for cellular communication related to MSCs' repairing function. What's more, the DEGs may even form complicated interaction networks and conjointly contribute to the MSCs' role in AD pathogenesis.

KEGG and GO analysis visualization (Figs. 5 and 6) suggested alteration in pathway and function of AD-MSCs compared with HD-MSC. KEGG prompted adhesion while GO indicated development. In that view, we believe MSCs in AD patients have some deficits in adhesion dysfunction, no matter at intercellular level or cell-matrix level. The deficit might contribute to AD pathogenesis but needs further investigation in vitro and in vivo. Cell adhesion, especially the adherence to ECM, is critical for determining cellular fates, such as proliferation, migration and differentiation both in vitro and in vivo (41). MSCs can produce various ECM components and thus promote the reconstruction of the aorta.

Finally, we must put out limitations of our study. Firstly, the sample size should have been larger. Given the constraints of funding and time, we finally adapted the sample size of $3+3$ for RNA-seq and $6+9$ for qRT-PCR. We believe the sample size is acceptable, for it at least ensures a repeat in triplicates. Besides, the between-group Pearson correlation coefficient (r) is significantly larger than within-group $\mathrm{r}(\mathrm{t}=4.0153$, $\mathrm{df}=10.895, \mathrm{P}=0.002071)$. Quality control has also confirmed the validity of our RNA-seq data. Secondly, the uncertainty of the causality. We currently cannot indisputably attribute these changes to either etiologic factors or disease results. We could only say these changes are associated with/related to AD in a certain way. Further validations of selected DEGs are needed, especially in vivo experiments. If alterations like mortality/morbidity or pathological changes on aortic walls are observed on KO mice, we then could say this gene indeed plays a part in AD. This is mainly due to constraints of time, funding and patient source. Thirdly, we did not strictly distinguish AD and aneurysm in our research. On the one hand, they are quite similar in pathogenesis and AD can result directly from aneurysm progression; and on the other hand, limitations come from current researches, that is, no very specific animal models for each disease. Additionally, no changes in MMP-2/9 are observed in our RNA-seq result, unfavourably. Actually, MMP-2/9 is one of our expected targets according to existing publications. A possible explanation, from our perspectives, might be that MMP-2/9 take effect as secretory factors in cell or tissue matrix, mainly at intercellular level. That's probably why didn't see a significant change on MMP-2/9.

In conclusion, the current study suggested there is a common molecular signature for AD-MSCs, and this signature is capable of distinguishing AD-MSCs from HD-MSCs. Moreover, changes in the expressed proteins suggested that AD-MSCs signaling and function alterations, especially adhesion and development related, could be an important factor in MSCs' effect on AD process. Our study creates a detailed transcriptome picture of the MSCs alteration in AD. And the molecular profile provides candidate genes for further study to definitively confirm their functions in MSCs for AD.

\section{Acknowledgements}

This study was funded by the National Natural Science Foundation of China (81570440 by Qu Lefeng and 81470576 by Liao Mingfang) and the Shanghai Science and Technology Talent Project (15YF1400500 by Zou Sili). We thank Professor Luyang Yu and all the staffs of Yu Laboratory, College of Life Sciences, Zhejiang University, for providing necessary technical support.

\section{References}

1. Hagan PG, Nienaber CA, Isselbacher EM, Bruckman D Karavite DJ, Russman PL, Evangelista A, Fattori R, Suzuki T, Oh JK, et al: The International Registry of Acute Aortic Dissection (IRAD): New insights into an old disease. JAMA 283: 897-903, 2000.

2. Schlatmann TJ and Becker AE: Pathogenesis of dissecting aneurysm of aorta. Comparative histopathologic study of significance of medial changes. Am J Cardiol 39: 21-26, 1977.

3. López-Candales A, Holmes DR, Liao S, Scott MJ, Wickline SA and Thompson RW: Decreased vascular smooth muscle cell density in medial degeneration of human abdominal aortic aneurysms. Am J Pathol 150: 993-1007, 1997.

4. De Bruin JL, Baas AF, Buth J, Prinssen M, Verhoeven EL, Cuypers PW, van Sambeek MR, Balm R, Grobbee DE and Blankensteijn JD; DREAM Study Group: Long-term outcome of open or endovascular repair of abdominal aortic aneurysm. N Engl J Med 362: 1881-1889, 2010.

5. SVN Task Force for Clinical Practice Guideline: 2009 Clinical practice guideline for patients undergoing endovascular repair of abdominal aortic aneurysms (AAA). J Vasc Nurs 27: 48-63, 2009.

6. Nabel EG, Yang Z, Liptay S, San H, Gordon D, Haudenschild CC and Nabel GJ: Recombinant platelet-derived growth factor B gene expression in porcine arteries induce intimal hyperplasia in vivo. J Clin Invest 91: 1822-1829, 1993.

7. Phinney DG and Prockop DJ: Concise review: Mesenchymal stem/multipotent stromal cells: The state of transdifferentiation and modes of tissue repair-current views. Stem Cells 25: 2896-2902, 2007.

8. Hashizume R, Yamawaki-Ogata A, Ueda Y, Wagner WR and Narita Y: Mesenchymal stem cells attenuate angiotensin II-induced aortic aneurysm growth in apolipoprotein E-deficient mice. J Vasc Surg 54: 1743-1752, 2011.

9. Schneider F, Saucy F, de Blic R, Dai J, Mohand F, Rouard H, Ricco JB, Becquemin JP, Gervais M and Allaire E: Bone marrow mesenchymal stem cells stabilize already-formed aortic aneurysms more efficiently than vascular smooth muscle cells in a rat model. Eur J Vasc Endovasc Surg 45: 666-672, 2013.

10. Davis JP, Salmon M, Pope NH, Lu G, Su G, Sharma AK, Ailawadi G and Upchurch GR Jr: Attenuation of aortic aneurysms with stem cells from different genders. J Surg Res 199: 249-258, 2015.

11. Zou S, Ren P, Zhang L, Azares AR, Zhang S, Coselli JS, Shen YH and LeMaire SA: AKT2 promotes bone marrow cell-mediated aortic protection in mice. Ann Thorac Surg 101: 2085-2096, 2016.

12. Shen YH, Hu X, Zou S, Wu D, Coselli JS and LeMaire SA: Stem cells in thoracic aortic aneurysms and dissections: Potential contributors to aortic repair. Ann Thorac Surg 93: 1524-1533, 2012.

13. Xie J, Jones TJ, Feng D, Cook TG, Jester AA, Yi R, Jawed YT, Babbey C, March KL and Murphy MP: Human adipose-derived stem cells suppress elastase-induced murine abdominal aortic inflammation and aneurysm expansion through paracrine factors. Cell Transplant 26: 173-189, 2017.

14. Sharma AK, Salmon MD, Lu G, Su G, Pope NH, Smith JR, Weiss ML and Upchurch GR Jr: Mesenchymal stem cells attenuate NADPH oxidase-dependent high mobility group box 1 production and inhibit abdominal aortic aneurysms. Arterioscler Thromb Vasc Biol 36: 908-918, 2016. 
15. Riera del Moral L, Largo C, Ramirez JR, Vega Clemente L, Fernández Heredero A, Riera de Cubas L, Garcia-Olmo D and Garcia-Arranz M: Potential of mesenchymal stem cell in stabilization of abdominal aortic aneurysm sac. J Surg Res 195: 325-333, 2015.

16. Ciavarella C, Alviano F, Gallitto E, Ricci F, Buzzi M, Velati C, Stella A, Freyrie A and Pasquinelli G: Human vascular wall mesenchymal stromal cells contribute to abdominal aortic aneurysm pathogenesis through an impaired immunomodulatory activity and increased levels of matrix metalloproteinase-9. Circ J 79: 1460-1469, 2015.

17. Dominici M, Le Blanc K, Mueller I, Slaper-Cortenbach I, Marini F, Krause D, Deans R, Keating A, Prockop Dj and Horwitz E: Minimal criteria for defining multipotent mesenchymal stromal cells. The international society for cellular therapy position statement. Cytotherapy 8: 315-317, 2006.

18. Nicoletti I, Migliorati G, Pagliacci MC, Grignani $F$ and Riccardi C: A rapid and simple method for measuring thymocyte apoptosis by propidium iodide staining and flow cytometry. J Immunol Methods. 139: 271-279, 1991.

19. Longo GM, Xiong W, Greiner TC, Zhao Y, Fiotti N and Baxter BT: Matrix metalloproteinases 2 and 9 work in concert to produce aortic aneurysms. J Clin Invest 110: 625-632, 2002.

20. Hackam DG, Thiruchelvam D and Redelmeier DA: Angiotensinconverting enzyme inhibitors and aortic rupture: A population-based case-control study. Lancet 368: 659-665, 2006.

21. Schouten O, van Laanen JH, Boersma E, Vidakovic R Feringa HH, Dunkelgrün M, Bax JJ, Koning J, van Urk H and Poldermans D: Statins are associated with a reduced infrarenal abdominal aortic aneurysm growth. Eur J Vasc Endovasc Surg 32: 21-26, 2006.

22. Yamawaki-Ogata A, Hashizume R, Satake M, Kaneko H, Mizutani S, Moritan T, Ueda Y and Narita Y: A doxycycline loaded, controlled-release, biodegradable fiber for the treatment of aortic aneurysms. Biomaterials 31: 9554-9564, 2010.

23. Baxter BT, Pearce WH, Waltke EA, Littooy FN, Hallett JW Jr, Kent KC, Upchurch GR Jr, Chaikof EL, Mills JL, Fleckten B, et al Prolonged administration of doxycycline in patients with small asymptomatic abdominal aortic aneurysms: Report of a prospective (Phase II) multicenter study. J Vasc Surg 36: 1-12, 2002.

24. Walton LJ, Franklin IJ, Bayston T, Brown LC, Greenhalgh RM, Taylor GW and Powell JT: Inhibition of prostaglandin E2 synthesis in abdominal aortic aneurysms: Implications for smooth muscle cell viability, inflammatory processes, and the expansion of abdominal aortic aneurysms. Circulation 100 48-54, 1999.

25. Yoshimura K, Aoki H, Ikeda Y, Fujii K, Akiyama N, Furutani A, Hoshii Y, Tanaka N, Ricci R, Ishihara T, et al: Regression of abdominal aortic aneurysm by inhibition of c-Jun N-terminal kinase. Nat Med 11: 1330-1338, 2005.

26. Bianco P, Riminucci M, Gronthos S and Robey PG: Bone marrow stromal stem cells: Nature, biology, and potential applications. Stem Cells 19: 180-192, 2001.

27. Matsumura G, Miyagawa-Tomita S, Shin'oka T, Ikada Y and Kurosawa H: First evidence that bone marrow cells contribute to the construction of tissue-engineered vascular autografts in vivo. Circulation 108: 1729-1734, 2003.

28. Allaire E, Muscatelli-Groux B, Guinault AM, Pages C, Goussard A, Mandet C, Bruneval P, Méllière D and Becquemin JP: Vascular smooth muscle cell endovascular therapy stabilizes already developed aneurysms in a model of aortic injury elicited by inflammation and proteolysis. Ann Surg 239: 417-427, 2004.
29. Sata M, Saiura A, Kunisato A, Tojo A, Okada S, Tokuhisa T, Hirai H, Makuuchi M, Hirata Y and Nagai R: Hematopoietic stem cells differentiate into vascular cells that participate in the pathogenesis of atherosclerosis. Nat Med 8: 403-409, 2002

30. Saiura A, Sata M, Hirata Y, Nagai R and Makuuchi M: Circulating smooth muscle progenitor cells contribute to atherosclerosis. Nat Med 7: 382-383, 2001.

31. Ryu JH, Park M, Kim BK, Ryu KH and Woo SY: Tonsil-derived mesenchymal stromal cells produce CXCR2-binding chemokines and acquire follicular dendritic cell-like phenotypes under TLR3 stimulation. Cytokine 73: 225-235, 2015.

32. Veréb Z, Póliska S, Albert R, Olstad OK, Boratkó A, Csortos C, Moe MC, Facskó A and Petrovski G: Role of human corneal stroma-derived mesenchymal-like stem cells in corneal immunity and wound healing. Sci Rep 6: 26227, 2016.

33. Li Q, Guo Y, Chen F, Liu J and Jin P: Stromal cell-derived factorpromotes human adipose tissue-derived stem cell survival and chronic wound healing. Exp Ther Med 12: 45-50, 2016.

34. Sharma AK, Lu G, Jester A, Johnston WF, Zhao Y, Hajzus VA, Saadatzadeh MR, Su G, Bhamidipati CM, Mehta GS, et al: Experimental abdominal aortic aneurysm formation is mediated by IL-17 and attenuated by mesenchymal stem cell treatment. Circulation 126 (11 Suppl 1): S38-S45, 2012.

35. Iida Y, Xu B, Xuan H, Glover KJ, Tanaka H, Hu X, Fujimura N, Wang W, Schultz JR, Turner CR and Dalman RL: Peptide inhibitor of CXCL4-CCL5 heterodimer formation, MKEY, inhibits experimental aortic aneurysm initiation and progression. Arterioscler Thromb Vasc Biol 33: 718-726, 2013.

36. Anzai A, Shimoda M, Endo J, Kohno T, Katsumata Y, Matsuhashi T, Yamamoto T, Ito K, Yan X, Shirakawa K, et al: Adventitial CXCL1/G-CSF expression in response to acute aortic dissection triggers local neutrophil recruitment and activation leading to aortic rupture. Circ Res 116: 612-623, 2015.

37. Tanios F, Pelisek J, Lutz B, Reutersberg B, Matevossian E, Schwamborn K, Hösel V, Eckstein HH and Reeps C: CXCR4: A potential marker for inflammatory activity in abdominal aortic aneurysm wall. Eur J Vasc Endovasc Surg 50: 745-753, 2015.

38. Michineau S, Franck G, Wagner-Ballon O, Dai J, Allaire E and Gervais M: Chemokine (C-X-C motif) receptor 4 blockade by AMD3100 inhibits experimental abdominal aortic aneurysm expansion through anti-inflammatory effects. Arterioscler Thromb Vasc Biol 34: 1747-1755, 2014.

39. Ramos-Mozo P, Rodriguez C, Pastor-Vargas C,Blanco-Colio LM, Martinez-Gonzalez J, Meilhac O, Michel JB, Vega de Ceniga M, Egido J and Martin-Ventura JL: Plasma profiling by a protein array approach identifies IGFBP-1 as a novel biomarker of abdominal aortic aneurysm. Atherosclerosis 221: 544-550, 2012.

40. Wang J, Razuvaev A, Folkersen L, Hedin E, Roy J, Brismar K and Hedin U: The expression of IGFs and IGF binding proteins in human carotid atherosclerosis, and the possible role of IGF binding protein-1 in the regulation of smooth muscle cell proliferation. Atherosclerosis 220: 102-109, 2012.

41. Giancotti FG and Ruoslahti E: Integrin signaling. Science 285 : 1028-1032, 1999. 